\title{
Alergia, urticaria de contacto y síndromes urticariformes inducidos por frío
}

\section{Allergy, cold contact urticarial and cold induced urticaria-like syndromes}

\author{
Beatriz Veleiro Pérez ${ }^{1}$, Mª Ángeles Rico Díaz y y Leticia Vila Sexto² \\ ${ }^{1}$ Servicio de Alergoloxía. ${ }^{2}$ Alergoloxía Infantil. Complexo Hospitalario Universitario A Coruña. SERGAS. A Coruña
}

\section{Introducción}

Es frecuente que en los servicios de alergología de nuestros hospitales se atiendan pacientes que han presentado erupciones cutáneas en relación con la exposición al frío. La mayoría se caracterizan por la aparición de prurito, eritema, urticaria y/o angioedema en las áreas de exposición 0 contacto con frío. Con menos frecuencia, podemos encontrarnos con pacientes que presentan brotes de una enfermedad sistémica tras haberse expuesto al frío, que debemos saber identificar y diagnosticar.

Los objetivos de este trabajo son recordar que el frío es capaz de desencadenar reacciones alérgicas y la revisión de diferentes "síndromes cutáneos" inducidos por frío, como la urticaria y algunas entidades pertenecientes al grupo de los síndromes autoinflamatorios familiares.

\section{Clasificación y datos epidemiológicos}

La urticaria por frío forma parte de las urticarias físicas, que son las desencadenadas por un estímulo mecánico. Dentro de ellas, ocupa el segundo lugar en frecuencia, por detrás del dermografismo o urticaria facticia, y el cuarto puesto entre las urticarias de larga duración ${ }^{1}$. En un estudio epidemiológico realizado por la Sociedad Española de Alergia, "Alergológica 2005", el frío fue la causa del 4,4 \% de los pacientes remitidos a nuestras consultas por urticaria crónica.

La urticaria por frío comprende una serie de trastornos heterogéneos. En términos generales podemos clasificarla en dos grandes grupos, adquirida o de origen familiar (tabla 1).

La mayoría de los cuadros adquiridos son diagnosticados mediante un test de exposición con frío, habitualmente un cubito de hielo, que explicaremos más adelante. Sin embargo, algunos pacientes con urticaria por frío adquirida no responden al test del cubito de hielo (urticarias adquiridas por frío atípicas) por lo que su diagnóstico se basa en la historia clínica y otros métodos diagnósticos.

Los cuadros familiares son excepcionales y, hasta el momento, se han descrito 3 grupos bien diferenciados, todos de herencia autosómica dominante: la urticaria familiar retardada por frío, la urticaria familiar por frío atípica (FACU) y el síndrome autoinflamatorio familiar inducido por frío (FCAS).
Tabla 1. Clasificación de la urticaria por frío

\begin{tabular}{|l}
\hline ADQUIRIDA \\
1. Urticaria por frío adquirida con test de exposición al frío positivo \\
-Primaria \\
-Secundaria: \\
Crioglobulinemia \\
Enfermedades infecciosas \\
$\quad$ Vasculitis leucocitoclástica \\
$\quad$ Miscelánea: picadura de insectos, medicamentos, neoplasias \\
2. Urticaria adquirida por frío con test de exposición al frío negativo \\
o con respuesta atípica: Urticaria adquirida atípica \\
-Urticaria por frío adquirida sistémica \\
-Dermografismo dependiente del frío \\
-Urticaria colinérgica inducida por frío \\
-Urticaria retardada por frío \\
-Urticaria retardada refleja \\
\end{tabular}

\section{Urticaria por frío adquirida: urticaria de contacto por frío}

De todos los cuadros comentados anteriormente (tabla 1), el más frecuente es la urticaria por frío adquirida. Dependiendo de las series, se corresponde con el 5-34\% de las urticarias físicas; esta variación depende de la región estudiada, ya que las incidencias más altas se corresponden con regiones de clima frío ${ }^{1}$. Los últimos documentos de posición y consenso de clasificación de urticarias se refieren a ella como urticaria de contacto por frío (cold contact urticaria, CCU) y así es como la denominaremos a partir de ahora. ${ }^{3,4}$

La rápida aparición de prurito, eritema, habones y/o angioedema en las áreas de contacto o exposición al frío es la característica fundamental de la urticaria de contacto por frío. Los desencadenantes pueden ser el aire, agua u objetos fríos y también la ingesta de alimentos o bebidas frías. Las lesiones aparecen rápidamente, minutos después de la exposición o contacto, y desaparecen en horas, casi siempre antes de dos horas. 
Solo algunos pacientes presentan edema orofaríngeo en relación con la ingesta de líquidos o alimentos fríos, lo que predice una mayor gravedad de la enfermedad, por existir mayor predisposición a presentar reacciones sistémicas ${ }^{5}$.

Lo habitual es que la expresión clínica se limite únicamente a la zona de contacto con el frío, pero cuando la extensión del área expuesta 0 el tiempo de duración del estímulo son amplios, pueden producirse reacciones generalizadas, que exceden el área de contacto 0 afectan a otros órganos distintos de la piel. La aparición de disnea, taquicardia, hipotensión y pérdida de conciencia son los síntomas más frecuentes.

Se han recogido casos de muerte por anafilaxia en pacientes con CCU durante el baño en agua fría. Por eso, es muy importante advertir a nuestros pacientes del peligro que conlleva la práctica de actividades acuáticas. El porcentaje de afectados con CCU que pueden presentar al menos una reacción sistémica varía entre 35 y 72\%7.

En el Servicio de Alergología del CHUAC hemos diagnosticado recientemente a una mariscadora que sufría cuadros sincopales durante su actividad laboral, trabajaba en las frías aguas de nuestra costa atlántica, que puede llegar a estar a $14015^{\circ} \mathrm{C}$. Ejercía su actividad laboral embutida dentro de un traje de neopreno. No objetivaba signos cutáneos por estar cubierta, sin embargo, tenía que ser asistida por sus compañeras continuamente por pérdida de conciencia. Se le realizó un estudio completo de síncope por distintos especialistas, que no encontraron patología orgánica. Fue remitida a nuestro servicio para "descartar alergia a anestésicos" tras presentar una anafilaxia intraoperatoria. Mediante un test de exposición con frío se le diagnosticó de una CCU, que justificaba toda su sintomatología previa y, en este caso, además confirmaba una enfermedad profesional. Se descartó alergia a los anestésicos locales empleados, por lo que concluimos que la anafilaxia intraoperatoria se debió a la administración de sueroterapia sin precalentamiento previo $\mathrm{y} / 0$ al ambiente frío del quirófano. Laxenaire y su equipo, en un estudio francés sobre las reacciones anafilácticas y anafilactoides en quirófano, encontraron que el $31 \%$ de las que no encontraban un fármaco como agente causal eran idiopáticas o el frío había sido el desencadenante principal ${ }^{8}$. De ahí que se deban tener en cuenta estos datos cuando se nos consulta por una anafilaxia intraoperatoria.

La CCU puede desencadenarse a cualquier edad, aunque es más frecuente en adultos jóvenes, y algo más en mujeres. Su incidencia anual estimada es de $0,05 \%{ }^{9}$. Es una enfermedad autolimitada, de duración media entre 5 y 8 años. Aproximadamente la mitad de los pacientes presentan remisión 0 mejoría clínica en los primeros 5 años. La aparición de síntomas en edad temprana confiere valor pronóstico, se ha confirmado que existe una correlación positiva entre la aparición de síntomas en edad temprana y la tendencia a presentar reacciones sistémicas ${ }^{10}$.

\section{Etiología y patogenia de CCU}

La principal célula implicada en la patogenia de la CCU es el mastocito, igual que ocurre en otras enfermedades alérgicas. En la sangre y en la piel de estos pacientes se han encontrado concentraciones elevadas de mediadores de la degranulación mastocitaria: histamina, factor de necrosis tumoral alfa (TNF-a), prostaglandina D2, el factor activador de plaquetas, factores quimiotácticos de eosinófilos y neutrófilos, y la sustancia $P$.

Además, hay datos que confirman que la lgE juega un importante papel en algunos casos. Hace años se hicieron estudios en los que al inyectar suero de paciente en la piel de un control sano, se transmitía pasivamente la reacción de contacto al frío. Al calentar el suero a $56^{\circ} \mathrm{C}$ se altera la cadena Fc de la lgE, perdiéndose la capacidad de unirse a los receptores, negativizándose la reacción de Prausnizt-Kustner ${ }^{11}$.

Lo que no se ha determinado todavía es el porqué se activa el mastocito, ni los mecanismos y señales que se producen cuando estos pacientes se exponen al frío.

Otro de los datos que apoya el papel de la lgE en la CCU es su mayor frecuencia en atópicos y su buena respuesta al tratamiento con omalizumab ${ }^{12}$.

La mayoría de las veces no se detecta ninguna causa que origine la CCU. En la literatura médica se han descrito casos de CCU secundarios a una enfermedad sistémica: la más frecuente es la asociada a la crioglobulinemia primaria o secundaria (leucemia linfoide crónica, linfosarcoma, vasculitis leucocitoclástica, VHC o linfadenopatía angioinmunoblástica). Sin embargo, la incidencia de CCU asociada a crioglobulinemia es baja, solo un 3\% de los pacientes que tienen crioglobulinemia presentan una urticaria por frío. Los pacientes con crioglobulinemia y CCU secundaria presentan algunas características diferenciadas: es más frecuente en mujeres, aparece alrededor de los 49 años, y se asocia a fenómeno de Raynaud, púrpura y necrosis cutánea. En estos casos, los síntomas asociados a la exposición al frío son mucho más graves.

También se han descrito asociaciones con infecciones virales y bacterianas (hepatitis, mononucleosis infecciosa, sifilis, Helicobacter pylori), y parasitarias (toxoplasmosis ${ }^{13}$ ). Otras infecciones del tracto urinario, dentarias y de la vía aérea superior pueden asociarse a CCU. Esto justificaría que ocasionalmente algunos pacientes se hayan beneficiado de tratamiento antibiótico. Aunque sin tanta consistencia, se han descrito asociaciones con la toma de algunos fármacos y con antecedentes de picadura de himenópteros. En algunos casos se ha asociado con la presencia de enfermedades hematológicas, linfáticas y neoplasias'. 


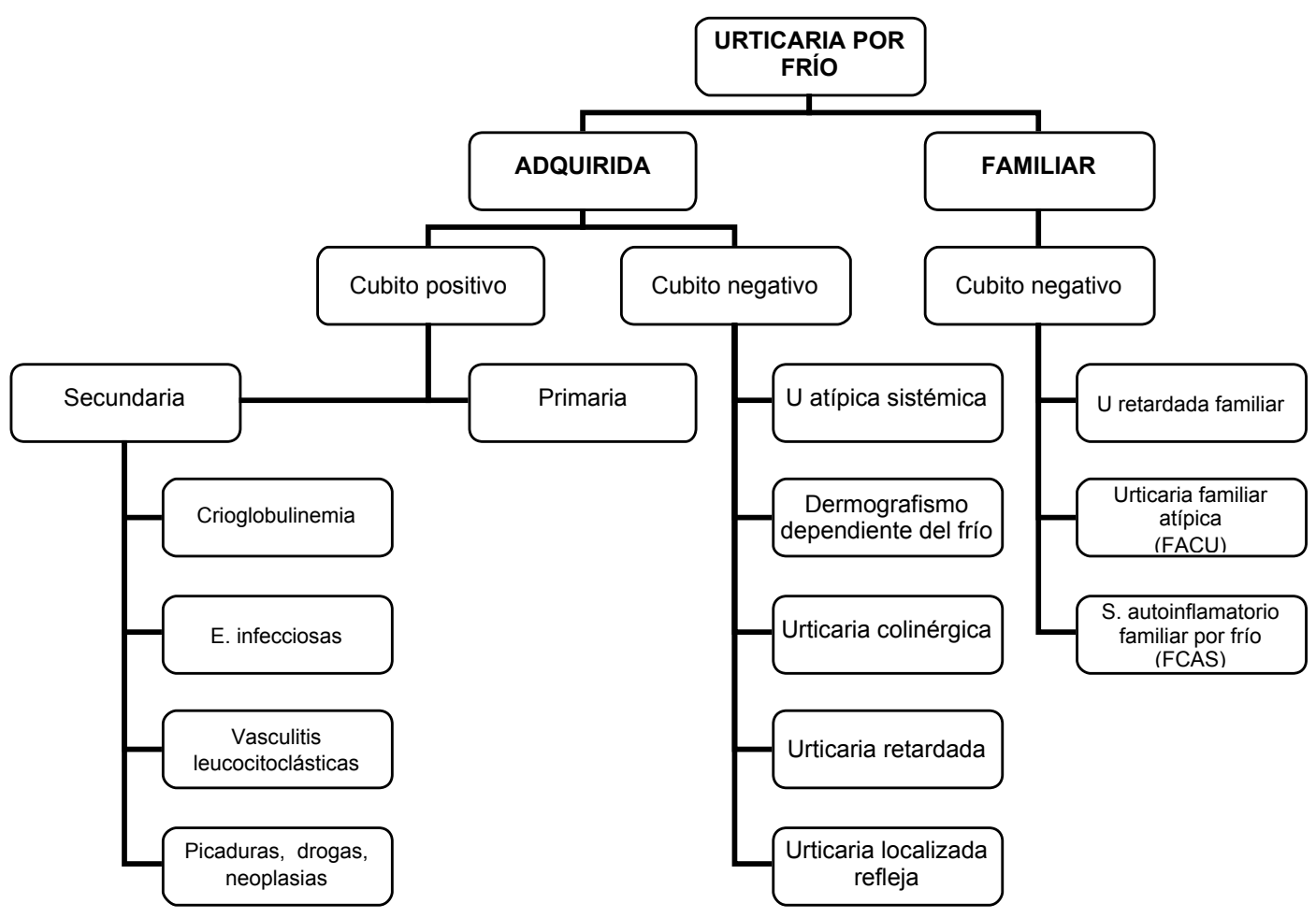

\section{Diagnóstico de CCU}

El diagnóstico se basa en la historia clínica y en la reproducción de las lesiones con un test de exposición con frío. Se ha descrito una clara relación entre la intensidad de las manifestaciones clínicas y la latencia de aparición de la respuesta al realizar el test de exposición.

En algunos países disponen para hacer la prueba de un dispositivo termoelectrónico, TempTest $₫$, que estimula simultáneamente la piel a diferentes temperaturas y tiempos de exposición. Pero el más empleado en nuestro medio es la exposición al frío con un cubito de hielo; la sensibilidad y especificidad del test es similar a la del dispositivo electrónico. Esta técnica no está exenta de riesgos, por ello hay que realizarla en una unidad preparada para resolver una reacción anafiláctica.

El test del cubito de hielo se realiza aplicando un cubito en la cara extensora del antebrazo durante un tiempo determinado, dependiendo de la gravedad de la reacción previa. La lectura se realiza 10 minutos después de retirarlo. El resultado es positivo si aparece una lesión sobreelevada, habonosa, en el área de aplicación. Es importante determinar el tiempo mínimo de exposición necesario capaz de inducir una reacción positiva, tiempo umbral de estimulación, al haberse demostrado que existe una relación inversa con la gravedad de la reacción. Por otra parte, el tiempo umbral puede servirnos para monitorizar la respuesta al tratamiento y valorar la evolución de la enfermedad. Un tiempo umbral de estimulación menor de tres minutos se correlaciona con mayor riesgo de presentar una reacción sistémica.
El resultado del test nos ayuda a diferenciar y clasificar los distintos trastornos asociados al frío (tabla 1, figura 1). La urticaria adquirida por frío se clasifica en dos grandes grupos, con test del cubito de hielo positivo y con test del cubito de hielo negativo o de respuesta atípica.

\section{¿Qué estudios de laboratorio debemos solicitar?}

Los estudios analíticos deben restringirse a aquellos pacientes en los que la historia clínica sugiere la existencia de una enfermedad subyacente. Si está indicado, solicitaremos un hemograma, bioquímica y perfil hepático, marcadores de inflamación como PCR y VSG, crioglobulinas, ANA y serologías virales y bacterianas. En la mayoría de los pacientes los estudios de laboratorio no mostrarán ninguna causa subyacente.

\section{Diagnóstico diferencial}

Cuando nos encontramos con un paciente que tiene una historia que sugiere una urticaria por frío, pero la respuesta a los test de exposición convencionales como el cubito de hielo es negativa, pueden hacerse con extremo cuidado otros test de provocación de áreas más amplias (bloques fríos o introducir el brazo en agua fría). Si son negativos o de respuesta atípica, sospecharemos una urticaria por frío atípica.

Las urticarias por frío atípicas son entidades clínicas muy raras, de las que apenas se han descrito casos aislados (tabla 2):

- Urticaria por frío sistémica: aparecen lesiones tras la exposición al aire frío o húmedo, pueden estar limitadas a la zona de contacto o generalizadas.

- Dermografismo dependiente del frío: se produce el dermografismo únicamente cuando se enfría la piel previamente. El 
test del cubito de hielo es negativo. Sin embargo, el dermografismo aparece con el roce en la piel enfriada previamente.

- Urticaria colinérgica inducida por frío: los habones de pequeño tamaño aparecen cuando se hace ejercicio en ambientes fríos. Pueden diagnosticarse haciendo correr al paciente en una cámara a $4^{\circ} \mathrm{C}$.

- Urticaria retardada por frío: aparecen las lesiones habonosas entre 12-48 horas después de la exposición al frío. El test del cubito es negativo a los 10 minutos, pero se positiviza horas después.

- Urticaria localizada refleja por frío: aparecen las lesiones inducidas por frío no en el área de exposición al frío, pero sí cerca de ella.

En los casos en los que hay una historia personal y/o familiar de aparición de lesiones habonosas en relación con el frío y, sin embargo, el test del cubito de hielo es negativo, también deben considerarse las formas familiares de urticaria por frío. Hasta el momento hay descritas 3 formas familiares, todas ellas muy poco frecuentes y de herencia autosómica dominante (tabla 3):

- La urticaria familiar retardada por frío.

- La urticaria familiar atípica por frío (FACU).

- El síndrome autoinflamatorio familiar por frío (FCAS), que se solapa con otras criopirinopatías.

\section{Urticaria familiar retardada por frío}

Los pacientes presentan lesiones eritematosas, pruriginosas y urticariformes entre 9 y 18 horas después de la exposición al frío, que se resuelven dejando una lesión hiperpigmentada residual. Tiene un patrón de herencia autosómica dominante. El test de estimulación con frío es negativo en lectura inmediata, pero se positiviza horas después.

\section{Urticaria familiar por frío atípica (FACU)}

Entidad clínica descrita en el año $2009^{14}$, de herencia autosómica dominante aunque no se ha detectado la mutación que la produce. Existen muy pocas familias descritas, donde los pacientes tienen episodios de urticaria inducida por frío a lo largo de toda la vida. Presentan eritema, prurito, urticaria y/o angioedema de aparición inmediata después del contacto directo con el ambiente frío o un objeto. La distribución del exantema parece relacionarse con la zona expuesta y en otras circunstancias, como con la natación, puede afectar a todo el cuerpo. Es característico que no esté acompañada de ninguna otra clínica sistémica (artralgias, fiebre, conjuntivitis), al contrario de lo que ocurre en el FCAS. Sin embargo, aunque el test de cubito de hielo es negativo, estos pacientes deben recibir el mismo tratamiento y medidas preventivas que los CCU.

\section{Síndrome autoinflamatorio familiar inducido por frío (FCAS)}

Antes se le conocía como urticaria familiar por frío, erupción polimorfa familiar por frío, hipersensibilidad por frío... y tradicionalmente estaba incluido dentro del espectro de la urticaria por frío. Sin embargo, aunque el aspecto de las lesiones papulosas es habonoso, la histopatología difiere de los habones propios de la urticaria convencional.

Este desorden de herencia autosómica dominante pertenece a los síndromes autoinflamatorios familiares, que tienen en común una alteración del sistema inmune innato, con poca o ninguna participación de las células T o B. Los pacientes comparten la presencia de fiebre y datos sistémicos de inflamación sin evidencia de la participación de ningún agente microbiano. En muchos de estos síndromes se ha detectado el gen responsable de esta respuesta inmune exagerada, y el listado de enfermedades autoinflamatorias hereditarias está en constante crecimiento ${ }^{15}$.

En concreto, el FCAS pertenece a los síndromes periódicos asociados a la criopirina (CAPS) o criopirinopatías, un grupo de síndromes autoinflamatorios familiares caracterizados por la sobreproducción de IL-1 $\beta$.

\section{¿Qué son las criopirinopatías (CAPS)?}

Las criopirinopatías son enfermedades raras de herencia autosómica dominante. Su incidencia en USA es de
Tabla 2. Urticarias adquiridas por frío atípicas

\begin{tabular}{|l|l|}
\hline Trastorno & Características clínicas \\
\hline $\begin{array}{l}\text { Urticaria por frío } \\
\text { sistémica }\end{array}$ & $\begin{array}{l}\text { El frío, aire húmedo inducen habones } \\
\text { localizados o generalizados }\end{array}$ \\
\hline $\begin{array}{l}\text { Dermografismo } \\
\text { dependiente de frío }\end{array}$ & $\begin{array}{l}\text { El dermografismo aparece solo en zonas de } \\
\text { la piel ya enfriadas }\end{array}$ \\
\hline $\begin{array}{l}\text { Urticaria colinérgica } \\
\text { por frío }\end{array}$ & $\begin{array}{l}\text { Urticaria generalizada con el ejercicio en } \\
\text { ambiente frío }\end{array}$ \\
\hline $\begin{array}{l}\text { Urticaria retardada por } \\
\text { frío }\end{array}$ & $\begin{array}{l}\text { Habones localizados 12-48 h después del } \\
\text { estímulo frío }\end{array}$ \\
\hline $\begin{array}{l}\text { Urticaria localizada } \\
\text { refleja }\end{array}$ & $\begin{array}{l}\text { Los habones aparecen cerca del lugar del } \\
\text { estímulo, pero no en el mismo lugar }\end{array}$ \\
\hline
\end{tabular}

Tabla 3. Urticarias familiares por frío

\begin{tabular}{|l|l|}
\hline Trastorno & Características clínicas \\
\hline $\begin{array}{l}\text { Urticaria familiar retardada } \\
\text { por frío }\end{array}$ & $\begin{array}{l}\text { Exantema urticariforme 9-18 horas } \\
\text { después del frío, puede resolverse con } \\
\text { hiperpigmentación }\end{array}$ \\
\hline $\begin{array}{l}\text { Urticaria familiar por frío } \\
\text { atípica (FACU) }\end{array}$ & $\begin{array}{l}\text { Habones de aparición inmediata después } \\
\text { del frío. }\end{array}$ \\
\hline $\begin{array}{l}\text { Síndrome autoinflamatorio } \\
\text { familiar por frío (FCAS) }\end{array}$ & $\begin{array}{l}\text { Exantema urticariforme 1-2 h después } \\
\text { del frío, artralgias, conjuntivitis, fiebre. } \\
\text { Mutación en NLRP3 }\end{array}$ \\
\hline
\end{tabular}


1/1000000, con una prevalencia de 300-500 individuos; en Francia, se estima que afecta a $1 / 360000^{16}$.

Comprenden tres entidades clínicas, aunque pueden ser consideradas como un "continuo" de expresiones fenotípicas de distinta gravedad de mutaciones en el gen NLRP3 (0 CIAS1), localizado en el cromosoma 1q44, que codifica la criopirina (figura 2).

Figura 2. Criopirinopatías

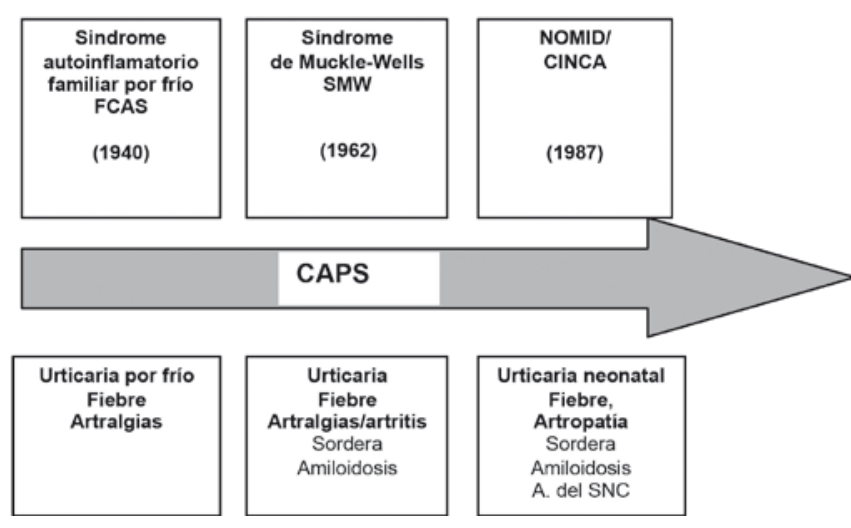

La criopirina es una proteína que participa en la regulación de la respuesta inmune innata. Forma complejos intracelulares denominados inflamasomas que intervienen en la maduración de la IL-1 $\beta$. Una alteración en esta vía va a producir la sobreproducción de IL-1 $\beta$ por los monocitos/macrófagos y condrocitos. El aumento de la IL-1 $\beta$ va a determinar todo el espectro de síntomas inflamatorios, fiebre, elevación de reactantes de fase aguda hepáticos y neutrofilia.

Las tres entidades clínicas, que pueden solaparse entre ellas y que forman el CAPS, son:

- El síndrome autoinflamatorio familiar inducido por frío (FCAS).

- El síndrome de Muckle-Wells (SMW).

- El neonatal onset multisystem inflammatory disorder o chronic, infantile neurological, cutaneous, and articular syndrome (NOMID/CINCA).
Como se ha comentado previamente, puede no haber fronteras entre el FCAS/SMW o el SMW/NOMID, comportándose como un continuo de fenotipos. Es posible que algunas mutaciones hasta ahora desconocidas pudieran servirnos para diferenciar mejor las tres entidades clínicas en un futuro (tabla 4). EI CAPS debe incluirse dentro del diagnóstico diferencial de los pacientes que presentan lesiones urticariformes inducidas por frío, a pesar de que en algunos fenotipos hay también otros desencadenantes. Por eso hablaremos del CAPS en esta revisión. Es importante tenerlo presente en la práctica clínica. Hasta ahora muchos pacientes con estos trastornos eran seguidos por distintos especialistas y diagnosticados de múltiples enfermedades sin llegar al diagnóstico etiológico ni a un manejo correcto de la enfermedad. En la actualidad, el mejor conocimiento de estas enfermedades y la posibilidad de realizar un estudio genético nos permite diagnosticar correctamente a estos pacientes, como nos ha ocurrido recientemente con una paciente que fue remitida a nuestro Servicio de Alergoloxía del CHUAC con un exantema urticariforme inducido por frío, que finalmente fue un CAPS (SMW) (figura 3).

\section{Síndrome autoinflamatorio familiar inducido por frío (FCAS)}

Es el fenotipo más leve de los CAPS. La exposición al frío es el principal desencadenante de la enfermedad, que cursa en brotes. Se describió inicialmente en los años 40. Se conoce desde entonces que es una enfermedad hereditaria, de patrón autosómico dominante, que afecta al $50 \%$ de la descendencia con penetrancia variable. Suele desencadenarse en el primer año de vida, habitualmente antes de los 6 meses. La edad de inicio de la enfermedad no parece relacionarse con su gravedad.

El aire acondicionado, el aire frío, cambios bruscos de temperatura... provocan una reacción inflamatoria sistémica que se manifiesta por fiebre, la aparición de un exantema urticariforme, inyección conjuntival y artralgias.

Tabla 4. Criopirinopatías

\begin{tabular}{|l|l|l|l|}
\hline CAPS & FCAS & SMW & NOMID/CINCA \\
\hline Herencia & HAD & HAD & HAD, de novo \\
\hline Locus, gen, proteína & 1q44, NLRP3, criopirina & 1q44, NLRP3, criopirina & La mayoría: 1q 44, NLRP3, criopirina \\
\hline Desarrollo & Infancia & Infancia & Período neonatal \\
\hline Duración brotes & Horas/días & Días/continuo & Continuo \\
\hline M. cutáneas & Exantema urticariforme por frío & $\begin{array}{l}\text { Exantema urticariforme por frío y otros } \\
\text { desencadenantes }\end{array}$ & Exantema urticariforme \\
\hline M. articulares & Poliartralgias & Poliartralgias/artritis & Artritis/deformidad articular \\
\hline M. neurológicas & Cefalea & Meningitis aséptica & Meningitis/retraso mental/atrofia óptica \\
\hline M. oculares & Conjuntivitis & Conjuntivitis/epiescleritis & Conjuntivitis/uveítis \\
\hline Amiloidosis secundaria & No & $25 \%$ & $\geq 25 \%$ \\
\hline
\end{tabular}


La latencia de exposición al frío y la aparición de los síntomas es variable, habitualmente de dos horas y media (rango entre 10 minutos y 8 horas $)^{17}$. Remite generalmente en menos de 24 horas, aunque puede durar hasta 72 horas, dependiendo del paciente.

El síntoma común que presentan todos los pacientes en los brotes es el exantema urticariforme, pruriginoso, pero también doloroso y urente. Puede aparecer en áreas no expuestas al frío. La anatomía patológica de las lesiones muestra un infiltrado neutrofílico, lo que la diferencia de otros tipos de urticaria. No presenta vasculitis y la inmunofluorescencia es negativa.

El siguiente síntoma en orden de frecuencia es la afectación articular, en forma de poliartralgias; sobre todo, afecta a las articulaciones de las manos, los dedos, rodillas, tobillos... No hay datos de artritis en los pacientes con FCAS. Los brotes se asocian con inyección conjuntival, fiebre y escalofríos. Se han descrito también otros síntomas como sudoración, somnolencia, cefalea, sed y náuseas.

Los estudios de laboratorio van a mostrar leucocitosis con neutrofilia, trombocitosis y elevación de los reactantes de fase aguda (VSG, PCR, fibrinógeno y haptoglobina) ${ }^{17}$.

\section{Síndrome de Muckle-Wells}

El síndrome de Muckle-Wells, descrito en el año 1962, es la criopirinopatía de gravedad intermedia. Se caracteriza por la presentación recurrente de la tríada:

- Fiebre, exantema urticariforme, artralgias y/o artritis, asociadas de dolor abdominal y conjuntivitis recurrente (figura 3).

- Hipoacusia neurosensorial progresiva.

- Amiloidosis secundaria con afectación renal.

La duración de los brotes es variable, entre 12 y 36 horas, de presentación intermitente, a intervalos regulares. La edad de inicio varía, pero suele comenzar en la infancia. El 100\% de los pacientes va a presentar un exantema urticariforme en relación con la exposición al frío, pero también con la humedad, el estrés, el calor... a diferencia de lo que sucede en el FCAS, en el que el frío juega un papel fundamental. En ocasiones no se detecta un desencadenante claro. El 75\% de los pacientes presentará artralgias y/0 artritis, no erosivas. La conjuntivitis recurrente es la forma de afectación ocular más frecuente, pero también se han descrito casos de uveítis anterior.

Pueden presentar cefalea e irritabilidad como manifestaciones neurológicas, producidas por una elevación de la presión intracraneal, relacionadas con meningitis crónica aséptica leve.

La sordera y amiloidosis secundaria no aparecen en los primeros años de la enfermedad. La sordera es neurosensorial y progresiva, afecta al $60 \%$ de los pacientes, se debe a una inflamación de la cóclea y órgano de Corti, que acaba por
Fig.3. Exantema maculopapular, urticariforme, en una paciente afecta de SMW

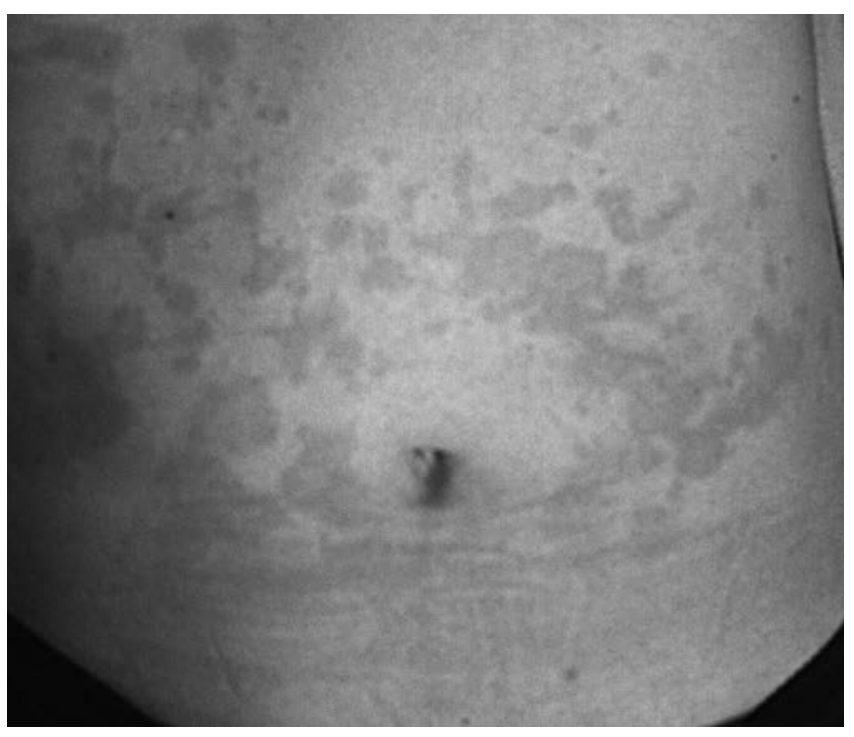

destruirse ${ }^{18}$. La amiloidosis aparece en la cuarta parte de los pacientes afectos de SMW, casi siempre en la tercera década de la vida, motivada por los procesos inflamatorios repetidos. Puede afectar a la mayoría de los órganos y tejidos, pero afecta principalmente al riñón, manifestándose como proteinuria, síndrome nefrótico e insuficiencia renal. La presencia de amiloidosis secundaria y la sordera ensombrecen el pronóstico de este síndrome.

\section{Neonatal onset multisystem inflammatory disorder (NOMID/CINCA)}

Fue descrita por vez primera en los años 80 y es la más grave de las criopirinopatías. La inflamación multiorgánica aparece ya en el período neonatal. Afecta a la piel en forma de "exantema urticariforme crónico", a las articulaciones y al SNC ${ }^{18}$. La afectación del SNC está presente en casi todos los pacientes y varía desde hipoacusia neurosensorial a la meningitis aséptica crónica y retraso mental, cefalea crónica, vómitos, irritabilidad y papiledema ${ }^{17}$. La afectación articular es más grave que en el SMW, con osteoartropatía sobre todo de huesos largos por sobrecrecimiento del cartílago epi-metafisario. El sobrecrecimiento rotuliano y del fémur distal es característico, dando lugar a deformaciones articulares. Hasta la tercera parte de los pacientes tienen dismorfia facial, con prominencia frontal, nariz en silla de montar e hipoplasia. La amiloidosis AA se desarrolla progresivamente con la edad, como en el SMW. Los pacientes pueden fallecer en edad temprana. Suelen encontrarse linfadenopatías y hepatoesplenomegalia.

\section{Diagnóstico de CAPS}

El diagnóstico de CAPS se basa en la historia clínica y su confirmación con el estudio genético, que mostrará mutaciones en NLRP3, el gen codificador de la criopirina. 
¿Qué determinaciones de laboratorio solicitamos?

Un hemograma con VSG y reactantes de fase aguda (PCR y proteína sérica amiloide), que debemos monitorizar para valorar la actividad de la enfermedad y la respuesta al tratamiento.

El hemograma mostrará leucocitosis con neutrofilia. Los niveles de reactantes de fase aguda (PCR) y proteína sérica amiloide (SAA) van a estar elevados. Es necesario solicitar niveles de creatinina y una analítica de orina para evaluar la función renal. Si se detecta proteinuria, habrá que descartar que exista un síndrome nefrótico, secundario a amiloidosis renal.

También debe realizarse una evaluación otorrinolaringológica para determinar si existe hipoacusia.

En ausencia de un estudio genético, el examen anatomopatológico de las lesiones cutáneas puede darnos una pista diagnóstica importante: existe un infiltrado neutrofílico intersticial en la dermis reticular característico. El infiltrado tiende a ser perivascular y puede ser periecrino. Este hallazgo es consistente con la urticaria "atípica" del CAPS, al no aparecer mastocitos en el infiltrado celular.

Dependiendo del órgano afectado podrá requerirse una punción lumbar, RMN (si hidrocefalia), valoración oftalmológica y un examen radiológico de las articulaciones.

\section{Tratamiento de la urticaria por frío y de las criopirinopatías}

\section{De la urticaria por frío}

El manejo práctico de los pacientes con urticaria por frío debe incluir medidas de evitación y prevención de reacciones sistémicas, tratamiento farmacológico de los episodios agudos, tratamiento de mantenimiento y monitorización de la respuesta al tratamiento.

\section{Educación para evitar la exposición al frío y prevenir las reacciones sistémicas.}

Los pacientes con CCU deben evitar la exposición al frío para prevenir la aparición de lesiones. Si se conoce el umbral de tiempo y temperatura necesarios para desencadenar una reacción es más fácil que el paciente sea capaz de controlar la exposición individualmente y así evitar síntomas en la vida cotidiana. En general, estos pacientes presentan merma de su calidad de vida.

Además de la prevención, el objetivo fundamental es evitar las reacciones sistémicas, por eso hay que instruirles en su reconocimiento y recomendarles que no practiquen actividades acuáticas ni consuman alimentos 0 bebidas frías para prevenir el edema orofaríngeo.

Una de las situaciones en las que un paciente con CCU puede presentar reacciones sistémicas es la cirugía. La temperatura de quirófano debe elevarse, y mantenerse al paciente lo más templado posible durante el procedimiento. Se re- comienda precalentar los fluidos y los hemoderivados a 37 ${ }^{\circ} \mathrm{C}$. Siguiendo la misma línea, también deben precalentarse medicamentos de administración endovenosa. El empleo de antihistamínicos antes de la intervención está justificado en los pacientes que hayan presentado reacciones sistémicas ${ }^{21}$.

\section{Tratamiento farmacológico de los episodios agudos.}

Otro de los pilares fundamentales es el adiestramiento en el tratamiento de una reacción aguda. Deben llevar en su kit de emergencia adrenalina, antihistamínicos y corticoides. Aquellos pacientes que hayan presentado una reacción anafiláctica deben llevar un autoinyector de adrenalina y nuestra obligación es explicarles cómo y cuándo deben emplearlo. En casos leves de urticaria y/0 angioedema sin compromiso aéreo, en los que la adrenalina no sea necesaria, deben tomar antihistamínicos y, si presentan angioedema importante, también puede ser útil un ciclo corto de corticoides.

Los antihistamínicos administrados antes de la exposición al frío son útiles para reducir los síntomas de la urticaria en las formas típicas.

\section{Tratamiento de mantenimiento.}

Los antihistamínicos son el pilar fundamental para el tratamiento de mantenimiento o profilaxis de la urticaria por frío adquirida. La ciproheptadina y doxepina se empleaban hace años con buena respuesta, sin embargo, sus efectos anticolinérgicos y sedativos han relegado su uso. Otros antihistamínicos no sedativos han demostrado su eficacia: cetirizina, ebastina, rupatadina, mizolastina y desloratadina ${ }^{7}$. Dependiendo de la clínica pueden ser empleados a demanda o de forma continuada. Algunos no responden a la dosis habitual, y se ha confirmado que la subida de dosis hasta 4 veces la dosis diaria recomendada es segura y eficaz ${ }^{22-25}$.

Si el tratamiento con antihistamínicos a altas dosis no controla los síntomas pueden añadirse anti- $\mathrm{H} 2 \mathrm{y}$ antagonistas de leucotrienos (zafirlukast, montelukast) ${ }^{26}$.

En los casos graves pueden intentarse tratamientos como ciclosporina durante los meses de invierno o pautas cortas de corticoides, sobre todo si hay evidencia de reacción de fase tardía 0 si el paciente va a estar expuesto al frío de forma prolongada.

Se ha demostrado la eficacia del tratamiento con anti-IgE (omalizumab), aunque en un número pequeño de pacientes ${ }^{27,28}$.

Otros tratamientos como la capsaicina tópica y la antibioterapia prolongada con penicilina fueron eficaces en algunos casos $^{29}$.

Las urticarias por frío adquiridas secundarias a alguna enfermedad suelen mejorar con el tratamiento de la enfermedad de base. 
Cuando el tratamiento farmacológico fracasa puede intentarse la inducción de tolerancia con frío. Los pacientes son desensibilizados exponiéndolos progresivamente al frío con suma precaución y bajo supervisión del especialista. Se comienza por exponer gradualmente una pequeña área del paciente a una temperatura superior a la temperatura umbral que desencadena los síntomas, posteriormente el área de contacto se va aumentando y disminuyendo la temperatura de exposición. La adherencia a este tratamiento suele ser mala porque los pacientes deben continuar exponiéndose a baños/duchas frías a diario para mantener el estado de tolerancia.

\section{Monitorización de la respuesta al tratamiento.}

Independientemente de la medicación con la que se maneje el cuadro clínico, deben realizarse test seriados de exposición al frío para valorar la respuesta al tratamiento. Hemos de tratar de alcanzar un tiempo umbral de positivización del test de exposición al frío mayor de 3 minutos. Si conseguimos este punto, nuestros pacientes presentarán menor riesgo de experimentar reacciones sistémicas durante la exposición al frío ${ }^{30}$.

\section{Tratamiento del FCAS y de las criopirinopatías}

El tratamiento con inhibidores de la IL-1 es el tratamiento de elección. Se están empleado distintos inhibidores de la IL-1 con muy buenos resultados: el Anakinra, inicialmente utilizado para el tratamiento de la artritis reumatoide, el Rilonacept y el último en aparecer, el Canakinumab (tabla 5).

Se administran vía subcutánea y apenas tienen efectos secundarios, los más frecuentes son dolor en el lugar de inyección y a veces cefalea. Como estos fármacos alteran la respuesta inmunológica debemos tener en cuenta que no puede iniciarse el tratamiento si hay una neutropenia previa. Debemos actualizar el calendario vacunal y completarlo. Es conveniente que los pacientes reciban la vacuna antigripal y antineumocócica. Para monitorizar la respuesta al tratamiento recomendamos la determinación de la proteína sérica amiloide y PCR antes de su inicio.
Los tres fármacos han demostrado ser muy eficaces en el tratamiento del CAPS.

La gran ventaja del Canakinumab respecto a los otros dos fármacos es que su pauta es bimensual gracias a su larga vida media de 26 días. Además, está aprobado desde el año 2009 para los tres tipos de CAPS a partir de los 4 años. Es un anticuerpo monoclonal frente a IL-1 $\beta$. Se ha demostrado su eficacia con la mejoría completa en 34 de 35 pacientes afectados de CAPS ${ }^{31}$.

El anakinra, un antagonista recombinante del receptor de la IL-1, de administración diaria, está aprobado en ficha técnica para la artritis reumatoide. Se comenzó a emplear por primera vez para el CAPS en el año 2003, y ha demostrado su eficacia en el FCAS y SMW, y no en todos los casos de NOMID. Puede reducir la proteinuria y estabilizar los niveles de creatinina ${ }^{32}$, se desconoce su impacto en la hipoacusia, aunque en algunos casos se ha detectado una recuperación parcial. Probablemente esto dependa del momento de inicio del tratamiento y si, cuando se inicia, ya hay daño irreversible ${ }^{33}$.

El rilonacept es una proteína de fusión, una IL- trap, aprobada desde el año 2008 para el FCAS y SMW en mayores de 12 años. Su vida media es de 8,6 días por lo que puede administrarse semanalmente, lo que le confiere cierta ventaja sobre el anakinra, pero es más cara. Se ha demostrado que reduce los síntomas y marcadores de inflamación pocos días después de iniciar el tratamiento ${ }^{16}$.

\section{Conclusiones}

Hemos repasado las manifestaciones clínicas, el diagnóstico y el tratamiento de los distintos trastornos que se producen por el frío (CCU) y de los síndromes en los que la exposición al frío (FCAS/SMW) y otros desencadenantes (SMW/NOMID) provocan brotes de enfermedad.

Debemos saber reconocer aquellos pacientes con una CCU en riesgo de presentar reacciones sistémicas y ofrecerles las medidas de prevención y tratamiento necesarias para

Tabla 5. Tratamiento del CAPS

\begin{tabular}{|l|l|l|l|l|}
\hline Fármaco & Acción & Vida media & $\begin{array}{l}\text { Pauta de administración } \\
\text { (subcutánea) }\end{array}$ & Indicación en ficha técnica \\
\hline Anakinra & Antagonista Rc-IL-1 & $4-6 \mathrm{~h}$ & Diaria & A. Reumatoide \\
\hline Rilonacept & Proteína de fusión, IL-1 trap & 8,6 días & Semanal & $\begin{array}{l}\text { FCAS } \\
\text { SMW } \\
(>12 \text { años })\end{array}$ \\
\hline Canakinumab & $\begin{array}{l}\text { mAb humanizado frente a } \\
\text { IL-1 } \beta\end{array}$ & 28 días & Bimensual & $\begin{array}{l}\text { FCAS } \\
\text { SMW } \\
\text { NOMID } \\
(>4 \text { años })\end{array}$ \\
\hline
\end{tabular}


que no se produzcan. Para valorar la respuesta al tratamiento y la evolución de la enfermedad es fundamental hacer un diagnóstico eficaz, con la determinación del tiempo umbral de positivización del test de frío y su monitorización posterior. Es importante recordar que el frío es capaz de inducir reacciones sistémicas, casi siempre con compromiso cardiovascular como síntoma cardinal, para tenerlo en cuenta dentro del diagnóstico diferencial de los cuadros sincopales no habituales.

Las criopirinopatías deben ser incluidas en el diagnóstico diferencial de cualquier paciente que presente un exantema urticariforme en relación con la exposición al frío, porque sus síntomas pueden ser atribuidos erróneamente a distintos trastornos y no ser tratados adecuadamente.

Como ocurre siempre en medicina, una buena historia clínica, en la que se haga hincapié en los antecedentes familiares de síntomas similares, puede ayudarnos a identificar a estos pacientes, que además tendrán en los fármacos anti-IL-1 al mejor aliado para mejorar su calidad de vida y, posiblemente, evitar la progresión de la enfermedad.

Agradecimientos: a la Dra. Pilar Iriarte, del Servicio de Alergoloxía de Ferrol, por su lectura y comentarios sobre este artículo.

\section{Puntos para recordar}

La CCU puede ser fácilmente diagnosticada con la historia clínica
y un test de exposición al frío. Es importante determinar el tiempo mínimo necesario para positivizar el test de exposición con frío. La detección del umbral de positividad es fundamental para monitorizar la respuesta al tratamiento y la evolución de la enfermedad.

Un tiempo de exposición de menos de 3 minutos indica alto riesgo de reacción sistémica.

El objetivo que perseguimos en la CCU es prevenir las reacciones sistémicas.

La CCU debe tenerse en cuenta en el diagnóstico de pacientes que consulten por cuadros sincopales sin causa aparente.

Los síndromes autoinflamatorios son trastornos hereditarios de la inmunidad innata, sin participación de linfocitos B y T o autoanticuerpos, por lo que no tienen nada que ver con las enfermedades autoinmunes.

Las criopirinopatías deben incluirse en el diagnóstico diferencial de los síndromes urticariformes inducidos por frío.

Los tres síndromes que conforman el CAPS hoy se consideran un continuo de expresiones fenotípicas de distinta gravedad de mutaciones del NLRP3.

La respuesta a los bloqueadores de la IL-1: anakinra, rilonacept y canakinumab es excelente, lo que sugiere la importancia de la $\| \mathrm{L}-1 \beta$ en la patogenia del CAPS.

\section{Bibliografía}

1. F. Siebenhaar, K.Weller, A. Mlynek, M. Magerl, S. Altrichter, R. Vieria dos Santos, M. Maurer and T. Zuberbier. Acquired cold urticaria: clinical picture and update on diagnosis and treatment. Clinical and Experimental Dermatology 2007; 32: 241-5.

2. SEAIC. Alergológica 2005. Factores epidemiológicos, clínicos y socioeconómicos de las enfermedades alérgicas en España en 2005. 2006; Luzán, S.A. de Ediciones.

3. M. Magerl, E. Borzova, A. Gimenez Arnau, et al. The definition and diagnostic testing of physical and cholinergic urticarias EAACI/GA2LEN/EDF/UNEV consensus panel recommendations. Allergy 2009; 64: 1715-21.

4. Zuberbier T, Asero R, Bindsley-Jensen $\mathrm{C}$, et al. EAACI/GA2LEN/EDF/WAO guideline: definition, classification and diagnosis of urticaria. Allergy 2009; 64: 1417-26.

5. Mathelier-fusade P, Aissaoui M, Bakhos D, et al. Clinical predictive factors of severity in cold urticaria. Arch Dermatol 1998; 13 (4): 106-107.

6. Brandes K. Cold urticaria and swimmer's death. Zeitschrift fur Allgemeinmedizin 1970; 46:119-20.

7. K Krause, Zuberbier, Maurer. Modern approaches to de diagnosis and treatment of cold contact urticaria. Curr Allergy Asthma Rep 2010; 10: 243-249.

8. Mertes PM, Laxenaire MC. Anaphylactic and anaphylactoid reactions ocurring during anaesthesia in France. Ann Fr Anaesth Reanim 2004; 23 (12): 1133-43.

9. Moller A, Henning M, Zuberbier T, Czarnetzki-Henz B. Epidemiology and clinical aspects of cold urticaria. Hautarzt 1996; 47: 510-4.

10. Katsarou-Katsari A, Makris M, Lagogianni E, et al. Clinical features and natural history of acquired cold urticaria in a tertiary referral hospital: a 10-year old prospective study. J Eur Acad Dermatol Venereol 2008; 22: 1405-1411.

11. M. Ferrer, E. Luquin, P. Gaig. Urticaria. En Tratado de Alergología. SEAIC. Tomo II. 2007; Ediciones Ergon.

12. J.A.Boyce. Succesfull treatment of cold induced urticaria-anaphylaxis with anti-lgE. J Allergy Clin Immunol 2006; 117: 1415-8.

13. Miralles López Jc, Lopez Andreu Fr, Sánchez-Gascón F, López Rodríguez C, Negro Álvarez Jm. Cold urticaria associated with acute serologic toxoplasmosis. Allergol Immunopathol (Madr) 2005; 33: 172-4.

14. Chavi Gandhi, Chris Healy, Alan A. Wanderer and Hal M. Hoffman. Familial atypical cold urticaria: Description of a new hereditary disease. J Allergy Clin Immunol 2009; 124 (6): $1245-50$.

15. V.U. Ozcurede and L. Franchi. Immunology in clinic review series; focus on autoinflammatory diseases: role of inflammasomes in autoinflammatory syndromes. Clinical and Experimental Immunology 2011;167: 382-390.

16. Takayo Miyame. Cryopyrin-associated Periodic Syndromes. Diagnosis and management. Pediatr Drugs 2012; 14 (2): 109-17.

17. I. Calvo Penadés, Berta López Montesinos, Ana Marco Puche. Med Clin (Barc). 2011; 136 (supl 1): 16-21.

18. Justin R Yu, Kieron S. Leslie. Cryopyrin-associated Periodic Syndrome: An update on diagnosis and treatment response. Curr Allergy Asthma Rep 2011; 11: 12-20.

19. Ahmadi N, Brewer CC, Zalewski C, et al. Cryopyrin-associated periodic syndromes: otolaryngologic and audiologic manifestacions. Otolaryngol Head Neck Surg 2011; 145:295-302.

20. Shinkai k, Mc Calmont TH, Leslie KS. Cryopyrin-associated periodic síndromes and autoinflammation. Clin Exp Dermatol 2008, 33 (1): 1-9.

21. Johnston WE, Moss J, Philbin DM, et al. Management of cold urticaria during hypothermic cardiopulmonary bypass. N Engl J Med 1982; 306: 219-21.

22. Siebenhaar F, Degener F, Zuberbier T, et al. High-dose desloratadine decreases wheal volume and improves cold provocation thresholds compared with standard-dose treatment in patients with acquired cold urticaria: a randomized, placebo-controlled, crossover study. J Allergy Clin Immunol 2009; 123:672-9.

23. Metz M, Sholz E, Ferrán M, et al. Rupatadine and its effects on symptom control, stimulation time, and temperature thresholds in patients with acquired cold urticaria. Ann Allergy Asthma Immunol 2010; 104:86-92.

24. Magerl M, Pisarevskaja D, Staubach P, et al. Critical temperature threshold measurement for cold urticaria: a randomized controlled trial of $\mathrm{H} 1$-antihistamine dose escalation. Br J Dermatol 2012; 166:1095-9.

25. Zuberbier T, Bindslev-Jensen C, Canonica W, et al. EAACI/GA2LEN/EDF guideline: management of urticaria. Allergy 2006; 61: 321-31.

26. Bonadonna P, Lombardi C, Senna G, et al.Treatment of acquired cold urticaria with cetirizine and zafirlukast in combination. J Am Acad Dermatol 2003; 49: 714-716.

27. Boyce JA. Succesful treatment of cold-induced urticaria/anaphylaxis with anti-lgE. J Allergy Clin Immunol 2006; 117:1415-8.

28. Metz M, Altrichter S, Ardelean E, et al. Anti-immunoglobulin E treatment of patients with recalcitrant physical urticaria. Int Arch Allergy Immunol 2011; 154:177-80.

29. Tóth-Kása I, Jancsó G, Obál F Jr, et al. Involvement of sensory nerve endings in cold and heat urticaria. J Invest Dermatol 1983; 80:34-6.

30. Alan A. Wanderer, Hal M. Hoffman. The spectrum of acquired and familial cold-induced urticaria/urticaria-like syndromes. Immunol Allergy Clin N Am 2004; 24: 259-86.

31. Lachmann HJ, Kone-Paut I, Kuemmerle-Deschner JB, et al. Use of canakinumab in the cryopirin-associated periodic syndrome. N Engl J Med 2009; 360:2416-25.

32. Leslie KS, Lachmann HJ, McDermott MF. Phenotype, genotype, and sustained response to anakinra in 22 patients with autoinflammatory disease associated with CIAS-1/ NALP3 mutations. Arch Dermatol 2006; 142: 1591-7.

33. Milraut $T$, Launay $D$, Cuisset $L$, et al. Recovery from deafness in a patient with MuckleWells syndrome treated with anakinra. Arthritis Rheum 2006; 54:1697-700. 